\title{
Conference Call
}

Life grows inexorably more complicated. Because of our increasing workload, we divide our time into smaller units as we try to give attention to larger numbers of projects. (Well, some of us. Perhaps, if we are careful, we can still protect our postdocs and graduate students from attention fragmentation.) The speed of the digital age drives us to do more, more and more quickly, as we no longer have the luxury of waiting for things coming in the mail. I miss those mailing delays, and the time to reflect that they imposed on every process involving a document. The very existence of modern communications technology demands that we use it, and it seems almost criminal not to make full use of the efficiency that is available to us. Every interstitial moment can be used, as we engage in multitasking or whatever the current term may be. I confess: I am writing this on a laptop computer, during a meeting, and most of the other attendees are clicking away, too. I wonder who is paying attention to the agenda.

We have now passed through the age of doing two things at a time and are on to the age of true parallel multitasking.

A typical day at the office used to be characterized by serial uni-tasking-we did one thing at a time, and worked at it until it was finished, we could go no further, or it was time to do something else. We have now passed through the age of doing two things at a time and are on to the age of true parallel multitasking. I can be on a conference call and simultaneously work on e-mail without giving too much offense (at least in this pre-videophone age), but I can also deal with visitors to my office through judicious use of the "mute" button on my hands-free phone, and can even sign a few forms while I am talking with a visitor. Attention to each individual task is a problem, of course, but we seem to have learned to cope with the compromise of quality in return for speed. This is where we are: We can mess up much faster and more effectively than ever before. Which of you has never sent a sensitive message out to the wrong list of e-mail recipients?

And yet greater "advances" are in the offing. I hardly ever go to the library anymore. That is a virtual activity these days, and in one way, the library I "go" to is much bigger than the ones I used to visit. Online information sources are improving daily, but my incidence of serendipitous finds among the current periodicals has 
markedly declined. Soon I won't have to go to the lab, either, with telepresence increasingly available in our laboratory equipment. I'm not so sure about this one, though-I suppose I am old-fashioned, but I like to twiddle the knobs on my electron microscope.

So, I can increasingly do all of my work without leaving my desk. How much longer will it be before I start to attend meetings online, too? The technology is certainly available, though the Internet bandwidth is still a little skimpy for an effective meeting with a serious number of participants. That will change soon enough. Consider the money and time savings that can be achieved: Gone are all the travel and lodging costs; gone is the travel time. Of course, this is the last remaining time when you cannot reliably multitask, and can maybe concentrate on something properly-depending on whom you are seated with or whether the seat in front of you reclines into your supertwist TFT screen. Long live the age of the laptop. Sign me up for the exit-row seat. Pack me an extra battery. And if you are working on technologies to allow my cell-phone to stay legally on during the flight, please stop. Now!

Even if bandwidth does increase to the point of making online meetings viable, I don't want to go that way. I have come to treasure the transit time that I spend incommunicado and able to get in some quality time with my word processor or my data. (Of course, I'm not too keen on the involuntary layovers that are now a random part of my life, as airline schedules move ever more into the category of fiction; but still, even these glitches are preferable to relentless, 24-7 multitasking.) Even more than the time spent in transit, I treasure the opportunities that a real conference brings for bumping into old friends, which happens with increasing regularity as you get older. It's purely a statistical phenomenon-the older you are, the more old (and long-lost) friends you have.

Real, live conferences have a number of scientific advantages over virtual ones, in addition to their social benefits. First of all, of course, you cannot multitask to any real extent at a conference, so you can concentrate on one thing at a time. The equipment exhibit is available as a distraction if you get a case of information overload. The show might be replaced by online advertising, perhaps, but the webniks have yet to come up with a real replacement for the giveaways that the vendors provide as come-ons. These have been very useful, over the years, as gifts for my kids, who seem to need some form of consolation when I get home from an

\section{Real, live conferences have a number of scientific advantages over virtual ones, in addition to their social benefits.}

extended absence. Although we have now grown out of this phase of development, I have been very gratified by the joy that can be brought to the soul of a fouryear old by the gift of a letter opener, mousepad, or brightly colored yardstick. Even a periodic table. (A really good idea would be for a vendor to come up with something suitable for a spouse who has been stuck with the kids for a week.)

Opinion-validation is another important benefit that is not available over the web. How often have you read a paper or seen a presentation and thought "nah!" or "duh?" or had some other carefully calibrated reaction other than "Excellent," "Very Good," "Good," "Fair," or "Poor?" The reaction from the crowd around you will tell you if you are on the mark or not, if you are at all sensitive to body language, and you just can't get that in a teleconference. The crowd also provides unfiltered information about what's hot and what's not, if you care to read it. Just walk along the hallways and look for the crowds spilling out of a session (taking note of whether they are trying to get IN or OUT) and you have all the information you need about the hot areas for funding in the next year or so. This is a bit like watching the stock market and realizing that you have just missed out on the next big thing, but you can still do well with that strategy if you are quick enough to react.

The real advantage of an MRS meeting, for me anyway, is the ability to look into topics that I normally don't have time for. I will often just drop in to a session to see what is going on or who is involved with it. The best strategy for this is to try to hit the invited talks, so a good meeting is one in which the invited talks don't all occur at $8: 30$ or 1:30. You need to get a proper flavor of a field by seeing some of the contributed papers, too; but especially if you are out of your own area, watch for that all-important crowd reaction as a guide to the importance of what you hear. A lot of murmuring at the back of the room is a sure sign that you haven't found the meatiest sandwich in the picnic basket.

Former MRS president Ron Gibala has noted that one way of dividing the world of MRS members is into the classes of "sitters" and "surfers." He and I are both inveterate surfers. Those of us who are apt to engage in this physical equivalent of channel-surfing can easily come into conflict with those who prefer to sit still and get a full dose of a single symposium. At best, we are only a little noisy between talks. If we rise to leave a little too quickly at the end of a talk, the session chair can mistake our rise from the seat as a sign of a burningly important question. (It pays to have a good question ready for moments like this, so you don't look like the idiot who waved to a friend at an auction and bought a painting.) We tend to stand at the back, or take the seats at the back or on the aisle, restricting movement for other, even more active surfers. More brazen surfers will struggle past placidly seated attendees to take a vacant seat and only avoid disturbing everyone in the room because we don't project slides from the rear of the room anymore. Then they'll leave again in the middle of the talk, after noisily consulting the program or their PDA. The worst of us clatter in or out through the loudest door in the midst of talks-often entering the room from behind or just in front of the speaker. And, of course, it is the surfers who form the crowds holding noisy discussions just outside the doors that they so thoughtfully hold open, in order to avoid banging them on their next entry or exit.

An especially obnoxious surfer is the one who is giving a talk and only arrives in the session minutes before it is scheduled. JIT*-style efficiency has as negative an effect on quality here as do the multitasking efficiencies I complained about. These are the speakers who will repeat introductory material that has been covered in three prior talks, and completely fail to put their work into the context of the ongoing session.

And worse, the surfers force bad behavior on other meeting attendees: It's usually easy to find a "sitter," but a "surfer" can only be found via the message board or (please, NO) their cell phone or pager.

But still, why go to the beach if you don't want to get in the water? The opportunity to learn something new is just too enticing to ignore, and I cannot give up my surfing ways. The MRS Fall Meeting convenes in Boston (on the shore of the Atlantic) in a few weeks. It's now conveniently located in a small geographical area, relative to our old three-hotel sprawl, and adherence to the schedule is (in my observation) ever improving. Conditions are ideal. Surf's up!

AlEx KING

*JTT stands for "just in time," terminology used in the manufacturing industries. Deliveries arrive "just in time" for use in the production line. 